\title{
Increased Malat1 Expression Predicts Poor Prognosis in Primary Gastrointestinal Diffuse Large B-cell Lymphoma
}

\section{Zhengzi Qian}

Tianjin Medical University Cancer Institute and Hospital: Tianjin Tumor Hospital

\section{Leiyuan Chen}

Tianjin Medical University Cancer Institute and Hospital: Tianjin Tumor Hospital

\section{Xinyuan Wang}

Tianjin Medical University Cancer Institute and Hospital: Tianjin Tumor Hospital

\section{Yutian Kan}

Tianjin Medical University Cancer Institute and Hospital: Tianjin Tumor Hospital

\section{Yafei Wang}

Tianjin Medical University Cancer Institute and Hospital: Tianjin Tumor Hospital

\section{Yong Yu}

Tianjin Medical University Cancer Institute and Hospital: Tianjin Tumor Hospital

\section{Xiaofang Wang}

Tianjin Medical University Cancer Institute and Hospital: Tianjin Tumor Hospital

\section{Zhigang Zhao}

Tianjin Medical University Cancer Institute and Hospital: Tianjin Tumor Hospital Hongliang Yang

Tianjin Medical University Cancer Institute and Hospital: Tianjin Tumor Hospital

\section{Peng Ge}

Tianjin Medical University Cancer Institute and Hospital: Tianjin Tumor Hospital

Tingting Ding

Tianjin Medical University Cancer Institute and Hospital: Tianjin Tumor Hospital Qiongli Zhai

Tianjin Medical University Cancer Institute and Hospital: Tianjin Tumor Hospital Haifeng Zhao ( $\square$ zhaohaifeng457@163.com )

Tianjin Medical University Cancer Institute and Hospital: Tianjin Tumor Hospital https://orcid.org/0000-0003-1585-9902

\section{Research Article}


Keywords: Primary gastrointestinal diffuse large B-cell lymphoma, Long non-coding RNA, MALAT1, Biomarker, Prognosis

Posted Date: March 11th, 2021

DOI: https://doi.org/10.21203/rs.3.rs-211838/v1

License: (1) This work is licensed under a Creative Commons Attribution 4.0 International License. Read Full License 


\section{Abstract}

Metastasis-associated lung adenocarcinoma transcript 1 (MALAT1) has been involved in the pathogenesis and progression of several cancers. However, the exact effect of MALAT1 in primary gastrointestinal diffuse large B-cell lymphoma (PGI-DLBCL) has not been elucidated. This study aimed to explore the prognostic value of MALAT1 in PGI-DLBCL patients. Quantitative real-time Polymerase Chain Reaction (qRT-PCR) was performed to detect the expression of MALAT1 in 90 patients with PGI-DLBCL. MALAT1 was remarkably up-regulated in PGI-DLBCL tissues as compared to that of paired adjacent nontumor tissues $(P<0.001)$, and the area under the ROC curve (AUC) was 0.838. MALAT1 expression was further increased in the non-germinal center B-cell-like (non-GCB) group, advanced stage (stages IIE-IV) group and International Prognostic Index (IPI) score (3-5) group $(P=0.01, P<0.001$ and $P<0.001$, respectively). Furthermore, Kaplan-Meier analysis showed that elevated MALAT1 expression was correlated with inferior Overall survival (OS) and progression free survival (PFS) in PGI-DLBCL patients $(P<0.001$ and $P<0.001$, respectively), and multivariate analysis suggested that up-regulation of MALAT1 and high IPI score (3-5) were two unfavorable prognostic factors of PGI-DLBCL. In conclusion, our results demonstrates that MALAT1 might serve as a novel prognostic biomarker and an ideal therapeutic target for PGI-DLBCL patients in the future.

\section{Introduction}

The most common extranodal site of non-Hodgkin's lymphoma $(\mathrm{NHL})$ is the gastrointestinal $(\mathrm{GI})$ tract, constituting about $5 \%-20 \%$ of all NHLs and $30 \%-40 \%$ of all extranodal lymphoma [1]. Primary GI (PGI) lymphoma is a relatively rare disease, accounting for only $1-4 \%$ of all GI malignant tumors [2]. The most frequently involved region is the stomach, followed by small intestine, ileum, cecum, colon and rectum $[3,4]$. Diffuse large B-cell lymphoma (DLBCL) is the most common histopathological subtype of PGI lymphoma, following mucosa-associated lymphoid tissue (MALT) lymphoma and follicular lymphoma, respectively $[5,6]$. The etiology of primary gastrointestinal diffuse large B-cell lymphoma (PGI-DLBCL) remains largely elusive. Recent studies have shown that long non-coding RNAs (IncRNAs) serve as new biomarkes for diagnosis and therapy of diverse cancers, and the aberrant expression are widely associated with pathogenesis, metastasis, and tumor stage [7-9]. To date, the molecular mechanism and clinical significance of IncRNAs on PGI-DLBCL patients has not been reported.

LncRNAs are the most abundant subclass of non-coding RNA, ranging in length from 200 nucleotides to 100,000 nucleotides, which have no protein coding ability and regulate various gene expression $[10,11]$. Recent evidences have demonstrated that IncRNAs play important roles in normal development and diseases including cancer, which involved in various biologic processes, such as cell proliferation [10], survival [12], differentiation [13], transcription regulation [14], genomic imprinting [15], $X$ chromosome inactivation [16]. The metastasis-associated lung adenocarcinoma transcript 1 (MALAT1), also known as nuclear enriched abundant transcript 2 (NEAT2), is one of the most widely studied IncRNAs with >8,000 nts, located on human chromosome 11q13 [17]. In 2003, MALAT1 was firstly discovered as a prognostic parameter indicating high metastatic potential and poor clinical outcomes in a study of gene expression 
differences in patients with stage I and stage II non-small cell lung cancer (NSCLC) [17]. Since then, research on MALAT1 has increased year-by-year $[18,19]$. The abnormal expression of MALAT1 has been found in many human cancers and was involved in the occurrence and development of tumors. Many studies have revealed that MALAT1 has an elevated expression and was associated with cancer progression in various solid tumors, including hepatocellular carcinoma [20], ovarian cancer [21], cervical cancer [22] and glioblastoma [23]. Reviewing the related studies of hematological malignant tumors, the role of MALAT1 in DLBCL [24], multiple myeloma (MM) [25], mantle cell lymphoma (MCL) [26] and acute myeloid leukemia (AML) [27] also has been studied.

There is a great deal of evidence supports abnormal patterns of expression of MALAT1 has been found in a wide variety of solid tumors and hematological malignancies, but the dysregulation of MALAT1 in PGIDLBCL patients has not been reported. Focusing on MALAT1 may provide new insights for PGI-DLBCL diagnosis, gene treatment and prognosis prediction. Therefore, this study was conducted to verify the potential effect of IncRNA MALAT1 in patients with PGI-DLBCL.

\section{Materials And Methods}

\section{Study subjects}

In this study, 90 cancer tissues (48 male and 42 female) and paired adjacent noncancerous tissues were obtained from patients who pathologically diagnosed with PGI-DLBCL in the Tianjin Medical University Cancer Institute and Hospital from 2011 to 2015. All patients did not receive radiotherapy or chemotherapy prior to surgery. All patients were randomly selected, with a balanced distribution of age and sex, no selection bias and no external validation. The PGI-DLBCL was confirmed diagnosis by two pathologists according to World Health Organization (WHO) classification system for hematologic malignancy [28]. Clinical stage of all PGI-DLBCL patients was classified according to the Lugano staging system for the Ann Arbor criteria for primary gastrointestinal non-Hodgkin's lymphoma [29]. The clinical and pathological features of the patients were obtained by medical record review. All of the experiments were approved by the Tianjin Medical University Cancer Institute and Hospital Ethics Committee and informed consent were obtained from all patients. All the tissues were frozen at $-80{ }^{\circ} \mathrm{C}$ for the next experiment.

\section{RNA and complementary deoxyribonucleic acid (cDNA) preparation}

Briefly, total RNA was isolated by TRIzol reagent (Invitrogen, Carlsbad, CA, USA) following the standard protocols. The concentrations and purity of RNA was measured the NanoDrop 2000 (NanoDrop Technologies, Waltham, USA). Following this, total RNA was reversed-transcribed to cDNA using a cDNA synthesis kit (Takara, Japan) according to the manufacturer's instruction. The generated cDNA was stored at $-20^{\circ} \mathrm{C}$ for later use.

\section{qRT-PCR}


According to the target gene, qRT-PCR primers were designed and synthesized, and the corresponding cDNA was used as template to amplify MALAT1. Each sample was detected with ABI PRISM-7500 Sequence Detection System (ABI Company, Oyster Bay, NY, USA). All the reactions were run in triplicate, and averages were calculated with Applied Biosystem 7500 software. The reaction was carried out at 95 ${ }^{\circ} \mathrm{C}$ for $10 \mathrm{~min}$, then denatured at $95^{\circ} \mathrm{C}$ for $15 \mathrm{~s}$, and then annealed at $60^{\circ} \mathrm{C}$ for $1 \mathrm{~min}$ for 40 cycles. The relative expression of glyceraldehyde phosphate dehydrogenase (GAPDH) was used as internal control to regulate the expression level of MALAT1. The $2^{-\triangle \triangle C t}$ method was used to determine the relative quantification of MALAT1 and GAPDH expression levels. The primers were as follows: MALAT1: F: 5'AACCAGTTTCCCCAGCTTTT-3'; R: 5'- CTACATTCCCACCCAGCACT -3'; GAPDH: F: 5'TGTGGGCATCAATGGATTTGG- 3'; R: 5'-ACACCATGTATTCCGGGTCAAT-3'.

\section{Immunohistochemical staining and scoring}

Immunohistochemical staining for CD10, B-cell lymphoma 6 (BCL-6) and Multiple myeloma antigen 1 (MUM1) in the tissue was performed. The sections were incubated with $3 \% \mathrm{H}_{2} \mathrm{O}_{2}$ at room temperature for 10 minutes and then washed with phosphate buffer saline (PBS). Next, the sections were stained for the following antibodies: CD10 (ZM0283, ZSGB-BIO, CA, USA), BCL-6 (ZM-0011, ZSGB-BIO, CA, USA) and MUM1(ZM0039, ZSGB-BIO, CA, USA) at $4{ }^{\circ} \mathrm{C}$ overnight. After washing in PBS again, the sections were incubated with secondary antibodies (PV6000, ZSGB-BIO, CA, USA). Finally, the reactivity was visualized by diaminobenzidine (DAB). The staining intensity and percentage of positive cells were recorded. Immunohistochemical analysis was independently reviewed by at least two experienced tissue pathologists.

\section{Treatment and response assessment}

The purpose of the operation is to remove the tumor tissue and obtain the pathological tissue. According to the National Comprehensive Cancer Network (NCCN) treatment guidelines, all patients received at least 4 cycles of standard dose CHOP or R-CHOP chemotherapy (rituximab, cyclophosphamide, doxorubicin, vincristine and prednisone) [30]. Tumor response was confirmed through CT, type-B ultrasonic and evaluated according to the International Working Group (IWG) response criteria as complete response $(C R)$, partial response (PR), stable disease (SD), and progressive disease (PD) [31]. Follow-up data were obtained from the outpatient reexamination and telephone. Overall survival (OS) is defined as the time from inclusion to death for any cause, and progressive-free survival (PFS) is defined as the time from inclusion to PD or any cause of death.

\section{Statistical analysis}

All statistical analyses were conducted using the SPSS20.0 (SPSS Inc, Chicago, USA) and GraphPadPrismV7.0 (GraphPad Software Inc) software. The relative expression level of MALAT1 in PGIDLBCL patients and paired adjacent non-tumor tissues was analyzed by Paired Student's t-test. Group comparisons were assessed also using the unpaired Students' t-test. Pearson Chi-square test was used to analyze the relationship between the expression of MALAT1 and the clinical characteristics of PGI-DLBCL 
patients. The cutoff value of tissues MALAT1 for predicting survival was determined by Receiveroperating characteristic (ROC) curve analysis. The analysis of survival curves was constructed by KaplanMeier method. Independent prognostic indicators were assessed in the multivariate and univariate analysis using Cox's proportional hazard model. ROC analysis was performed and the area under the ROC curve (AUC) was calculated to explore whether the levels of MALAT1 expression could be used as a diagnostic biomarker of PGI-DLBCL. Data were summarized as mean \pm standard deviation (SD). In all tests, $\mathrm{P}<0.05$ was considered as statistically significant.

\section{Results}

\section{Increased expression and diagnostic value of MALAT1 in PGI-DLBCL}

To investigate the role of MALAT1 in PGI-DLBCL, the expression of MALAT1 in 90 cases of PGI-DLBCL tissues and normal tissues was detected by qRT-PCR. The median expression level of MALAT1 in tumor tissues was 21.8 (range 1.1 to 58.4). The median level of MALAT1 expression in adjacent non-cancer tissues was 5.8 (range 0.1 to 20.5), which was significantly lower than that in PGI-DLBCL patients' tumor tissues $(P<0.001$, Fig. 1$)$.

ROC curves were constructed to determine whether MALAT1 could be used as a diagnostic biomarker of PGI-DLBCL. The AUC value is 0.838 ( $P<0.001$, Fig. 2). According to the analysis of ROC curve, the most significant critical point of MALAT1 was 11.4 , and the sensitivity and specificity were $75.6 \%$ and $70 \%$, respectively. Based on the cutoff value, 23 cases (25.6\%) were divided into low-MALAT1group ( $\leq 11.4)$ and 67 cases $(74.4 \%)$ were divided into high-MALAT1 group (>11.4).

\section{Clinicopathological significance of MALAT1 in PGI-DLBCL}

Ninety patients with PGI-DLBCL were recruited for the study. Sixty-nine patients (76.7\%) affected region are the stomach. Using the Lugano staging system, 50 patients (55.6\%) were diagnosed as advanced disease (IIE-IV stage). Sixty-nine patients (76.7\%) exhibited a good performance status (0-1). All cases were stained for BCL6, CD10 and MUM1, of which 37 cases (41.1\%) were GCB subtype and 53 cases (58.9\%) were non-GCB subtype. Elevated LDH levels in 58 patients $(64.4 \%), B$ symptoms were identified in 60 patients $(66.7 \%)$ and low IPI scores (0-2) were found in 54 cases $(60.0 \%)$. Of these, lymph node metastasis in 47 patients $(52.2 \%)$ and bone marrow metastasis was found in 24 patients $(26.7 \%)$. In total, there were 55 patients (61.1\%) treated with 4-8 cycles of the R-CHOP regimens.

In order to further understand the clinical role of MALAT1 in PGI-DLBCL, we analyzed the relationship between MALAT1 expression and clinicopathological features of patients. General data of all patients in this study are summarized in Table 1. From the data, the MALAT1 level was significantly higher in patients with non-GCB pathological type $(P=0.006)$, advanced Lugano stage $(\mathbb{E}-\mathrm{X})(\mathrm{P}<0.001)$, high IPI score (3-5) $(P=0.018)$ and bone marrow metastasis $(P=0.024)$. In contrast, no significant statistical differences were observed in the subgroup of other clinical features, such as sex, age, tumor origin, performance status, treatment and lymph node metastasis. Subsequently, we further analyzed the 
expression level of MALAT1 in pathological type, Lugano stage and IPI score. The result demonstrated that MALAT1 expression was significantly associated with non-GCB subtype, advanced $\triangle \mathrm{E}-\mathbb{\square}$ stage and high IPI subgroup ( $P=0.01, P<0.001$ and $P<0.001$, Fig. 3a, Fig. 3b, Fig. 3c).

\section{Prognostic importance of MALAT1 in PGI-DLBCL}

Kaplan-Meier method was used to evaluate the effect of MALAT1 levels on the prognosis of PGI-DLBCL patients. As expected, the survival analysis showed that the OS of patients with high MALAT1 expression was significantly worse than that of patients with low MALAT1 expression $(P<0.001$, Fig. 4a). Similarly, the PFS of the high-MALAT1 group was significantly shorter than that of the low-MALAT1 group $(P<0.001$, Fig. 4b). In univariate and multivariate analysis, we discovered that elevated MALAT1 expression and high IPI score had adverse effects on OS and PFS, while the non-GCB subtype was an unfavourable risk factor for OS (Table 2).

\section{Discussion}

PGI-DLBCL is an aggressive malignancy and commonly shows with some nonspecific clinical manifestations, such as gastric pain, dyspepsia, weight loss, gastric perforation, gastrointestinal bleeding and so on, possibly as a consequence of late diagnosis [32]. Additionally, PGI-DLBCL presents as a clinically heterogeneous tumor, which is generally treated with the standard CHOP or R-CHOP regimen [33]. Despite an improvement in the clinically comprehensive treatment of PGI-DLBCL, the prognosis of refractory or relapsed disease remains poor [34,35]. Hence, further researches are urgently needed to explore the molecular mechanism of PGI-DLBCL development and search for novel prognostic biomarkers and/or potential targets, ultimately making effective individual treatments to improve outcomes.

At present, researchers have found a large number of IncRNAs and proved that they were related to the occurrence and development of human diseases, especially in cancers, which could promote cancer cell proliferation, invasion and metastasis [36]. Emerging reports have shown that IncRNAs can be used as biomarkers to predict the diagnosis and prognosis of human tumors as well as therapeutic targets for tumor treatment. In this study, we discovered that the expression of MALAT1 in PGI-DLBCL was significantly higher than that in adjacent nontumor tissues, and ROC curve analysis showed that the AUC value was 0.882 , indicating that MALAT1 has potential diagnostic value for PGI-DLBCL. Moreover, we observed that MALAT1 is tightly related to some clinical parameters, including pathological subtypes, Lugano staging status, IPI score and bone marrow metastasis. Through the Kaplan-Meier analysis, the results indicated that patients with high MALAT1 expression had worse OS and PFS than those with low MALAT1 expression. Combined univariate and multivariate analysis revealed that MALAT1 expression and IPI score were risk factors for OS and PFS in patients with PGI-DLBCL.

As aforementioned, MALAT1 displays a vital role in the pathogenesis and progression of diverse cancers and increasing efforts have been devoted to developing MALAT1-based cancer diagnosis and treatment. However, the mechanism of MALAT1 gene expression affecting prognosis of PGI-DLBCL remains to be 
fully elucidated. Recent studies have validated that MALAT1 was involved in diverse biological processes, including cell proliferation, cell death, cell cycle, migration and invasion, via modulation of certain signaling pathways, including MAPK/ERK, PI3K/AKT, WNT/ $\beta$-catenin and NF-kB, promoting tumor growth and metastasis [37-42]. MALAT1 has been reported to promote gastric cancer (GC) cell proliferation partly by recruiting SF2/ASF, a crucial member of serine/arginine-rich protein (SR) family proteins, making a potential biomarker and a therapeutic target for GC diagnosis and treatment [43]. In addition, several previous investigations have demonstrated that MALAT1 induces tumorigenesis and evolution through other molecular mechanisms, including binding to the active chromatin sites and regulating alternative splicing [44,45]. It should be noted that MALAT-1 was upregulated in DLBCL cells, and MALAT-1 silencing can decrease chemotherapy resistance by enhancing autophagy [46]. On the other hand, MALAT1 has been verified to induce DLBCL progression by regulation of miR-195 and PD-L1, then promoted epithelialmesenchymal transition (EMT) process via Ras/ERK signaling pathway [24].

The IPI is the relatively valuable and widely used prognostic tool for almost all subtypes of non-Hodgkin's lymphoma [47]. The limitation is that the IPI evaluation system includes only a small number of clinical features and does not take into account the molecular biology of tumors. Currently, accumulating studies are performed to explore other risk factors affecting survival in PGI-DLBCL. A previous study has shown that the prognosis of patients with non-GCB is worse than that of patients with GCB [48]. Unfortunately, our study displayed no significant difference between MALAT1 expression and pathological subtypes. Ye et al. [49] discovered that MLL2 protein overexpression in PGI-DLBCL was positively related to higher clinical stage and negatively related to elderly patients (age >60 years) survival. Chen et al. [50] study demonstrated that upregulation of Mad2 might facilitate cell proliferation in PGI-DLBCL, and patients with higher Mad2 expression had inferior disease free survival (DFS). Similarly, our findings suggested that MALAT1 was increased in PGI-DLBCL and patients with elevated MALAT1 expression exhibited unfavorable outcomes, indicating MALAT1.

The present study also has some shortcomings: First, due to the limited sample, we can not get enough samples from other extranodal lymphoma patients, leading to fail to evaluate the role of MALAT1 expression in other extranodal lymphomas. Second, this study confirmed that MALAT1 had the predictive potential to PGI-DLBCL prognosis. However, owing to the limitation of samples, the present study does not independently verify the sample settings, and it is impossible to verify whether there are the same results in different samples. This needs to be further verified by expanding the sample size and including other patients with extranodal lymphoma in future studies.

In conclusion, our work presented that MALAT1 can be considered as a novel diagnostic and prognostic biomarker in PGI-DLBCL. A larger sample size is needed in the future in order to better understand the mechanisms of MALAT1 in the molecular etiology of PGI-DLBCL.

\section{Declarations}


Funding This study was financially supported by National Natural Science Foundation of China (No. 81100337, 81470283).

\section{Conflicts of interest None.}

Availability of data and material The datasets generated and analyzed during the current study available from the corresponding author on reasonable request.

Code availability Not applicable.

Authors' contributions ZHF designed the study and review the final manuscript. QZZ, CLY and WXY performed the experiment, analyzed the experimental data and wrote the manuscript. KYT helped to perform the experiment. WYF, YY, WXF, ZZG and YHL collected the clinical information of the patients and collected the specimens. GP, DTT and ZQL helped to collect the specimens. All authors read and approved the final manuscript.

Ethics approval All procedures carried out in studies involving human participants are consistent with the ethical standards of our institutional review committee and the 1964 Helsinki Declaration and its subsequent amendments or similar ethical standards.

Consent to participate All contributors provided written informed consent for participating in the entire study.

Consent for publication This manuscript is approved by all authors for publication.

Acknowledgments This study was financially supported by National Natural Science Foundation of China (No. 81100337, 81470283).

\section{References}

1. Nakamura S, Matsumoto T. Gastrointestinal lymphoma: recent advances in diagnosis and treatment. Digestion. 2013;87(3):182-188.

2. Wang T, Gui W, Shen Q. Primary gastrointestinal non-Hodgkin's lymphoma: clinicopathological and prognostic analysis. Med Oncol. 2010;27(3):661-666.

3. Papaxoinis G, Papageorgiou S, Rontogianni D, et al. Primary gastrointestinal non-Hodgkin's lymphoma: a clinicopathologic study of 128 cases in Greece. A Hellenic Cooperative Oncology Group study (HeCOG). Leuk Lymphoma. 2006;47(10):2140-2146.

4. Koch P, del Valle F, Berdel WE, et al. Primary gastrointestinal non-Hodgkin's lymphoma: I. Anatomic and histologic distribution, clinical features, and survival data of 371 patients registered in the German Multicenter Study GIT NHL 01/92. J Clin Oncol. 2001;19(18):3861-3873.

5. Nakamura S, Matsumoto T, lida M, Yao T, Tsuneyoshi M. Primary gastrointestinal lymphoma in Japan: a clinicopathologic analysis of 455 patients with special reference to its time trends. Cancer. 
2003;97(10):2462-2473.

6. Nagakita K, Takata K, Taniguchi K, et al. Clinicopathological features of 49 primary gastrointestinal diffuse large B-cell lymphoma cases; comparison with location, cell-of-origin, and frequency of MYD88 L265P. Pathol Int. 2016;66(8):444-452.

7. Schmitt AM, Chang HY. Long Noncoding RNAs in Cancer Pathways. Cancer Cell. 2016;29(4):452-463.

8. Bartonicek N, Maag J, Dinger M. Long noncoding RNAs in cancer: mechanisms of action and technological advancements. Mol Cancer. 2016;15(1):43.

9. Bhan A, Soleimani M, Mandal S. Long Noncoding RNA and Cancer: A New Paradigm. Cancer Res. 2017;77(15):3965-3981.

10. Ponting CP, Oliver PL, Reik W. Evolution and functions of long noncoding RNAs. Cell. 2009;136(4):629-641.

11. lyer MK, Niknafs YS, Malik R, et al. The landscape of long noncoding RNAs in the human transcriptome. Nat Genet. 2015;47(3):199-208.

12. Shen J, Siegel AB, Remotti H, Wang Q, Shen Y, Santella RM. Exploration of Deregulated Long NonCoding RNAs in Association with Hepatocarcinogenesis and Survival. Cancers (Basel). 2015;7(3):1847-1862.

13. Cesana M, Cacchiarelli D, Legnini I, et al. A long noncoding RNA controls muscle differentiation by functioning as a competing endogenous RNA. Cell. 2011;147(2):358-369.

14. Martianov I, Ramadass A, Serra Barros A, Chow N, Akoulitchev A. Repression of the human dihydrofolate reductase gene by a non-coding interfering transcript. Nature. 2007;445(7128):666670.

15. Sleutels F, Zwart R, Barlow DP. The non-coding Air RNA is required for silencing autosomal imprinted genes. 2002;415(6873):810-813.

16. Tian D, Sun S, Lee JT. The long noncoding RNA, Jpx, is a molecular switch for $\mathrm{X}$ chromosome inactivation. Cell. 2010;143(3):390-403.

17. Ji P, Diederichs S, Wang W, et al. MALAT-1, a novel noncoding RNA, and thymosin beta4 predict metastasis and survival in early-stage non-small cell lung cancer. Oncogene. 2003;22(39):8031-8041.

18. Amodio N, Raimondi L, Juli G, et al. MALAT1: a druggable long non-coding RNA for targeted anticancer approaches. J Hematol Oncol. 2018;11(1):63.

19. Li ZX, Zhu QN, Zhang HB, Hu Y, Wang G, Zhu YS. MALAT1: a potential biomarker in cancer. Cancer Manag Res. 2018;10:6757-6768.

20. Malakar P, Shilo A, Mogilevsky A, et al. Long Noncoding RNA MALAT1 Promotes Hepatocellular Carcinoma Development by SRSF1 Upregulation and mTOR Activation. Cancer Res. 2017;77(5):1155-1167.

21. Gordon M, Babbs B, Cochrane D, Bitler B, Richer J. The long non-coding RNA MALAT1 promotes ovarian cancer progression by regulating RBFOX2-mediated alternative splicing. Mol Carcinog. 2019;58(2):196-205. 
22. Shen F, Zheng H, Zhou L, Li W, Xu X. Overexpression of MALAT1 contributes to cervical cancer progression by acting as a sponge of miR-429. J Cell Physiol. 2019;234(7):11219-11226.

23. Voce DJ, Bernal GM, Wu L, et al. Temozolomide treatment induces IncRNA MALAT1 in an NF-small ka, CyrillicB and p53 co-dependent manner in glioblastoma. Cancer Res. 2019;79(10):2536-2548.

24. Wang QM, Lian GY, Song Y, Huang YF, Gong Y. LncRNA MALAT1 promotes tumorigenesis and immune escape of diffuse large B cell lymphoma by sponging miR-195. Life Sci. 2019;231:116335.

25. Cho SF, Chang YC, Chang CS, et al. MALAT1 long non-coding RNA is overexpressed in multiple myeloma and may serve as a marker to predict disease progression. BMC Cancer. 2014;14:809.

26. Wang X, Sehgal L, Jain N, Khashab T, Mathur R, Samaniego F. LncRNA MALAT1 promotes development of mantle cell lymphoma by associating with EZH2. J Transl Med. 2016;14(1):346.

27. Hu N, Chen L, Wang C, Zhao H. MALAT1 knockdown inhibits proliferation and enhances cytarabine chemosensitivity by upregulating miR-96 in acute myeloid leukemia cells. Biomed Pharmacother. 2019;112:108720.

28. Turner JJ, Hughes AM, Kricker A, et al. WHO non-Hodgkin's lymphoma classification by criterionbased report review followed by targeted pathology review: an effective strategy for epidemiology studies. Cancer Epidemiol. Biomarkers Prev. 2005;14(9):2213-2219.

29. Rosolen A, Perkins SL, Pinkerton CR, et al. Revised International Pediatric Non-Hodgkin Lymphoma Staging System. J Clin Oncol. 2015;33(18):2112-2118.

30. Horwitz SM, Zelenetz AD, Gordon LI, et al. NCCN Guidelines Insights: Non-Hodgkin's Lymphomas, Version 3.2016. J Natl Compr Canc Netw. 2016;14(9):1067-1079.

31. Cheson BD, Pfistner B, Juweid ME, et al. Revised response criteria for malignant lymphoma. J Clin Oncol. 2007;25(5):579-586.

32. Peng JC, Zhong L, Ran ZH. Primary lymphomas in the gastrointestinal tract. J Dig Dis. 2015;16(4):169-176.

33. Ghimire P, Wu G, Zhu L. Primary gastrointestinal lymphoma. World J Gastroenterol. 2011;17(6):697707.

34. Ishikawa E, Nakamura M, Shimada K, et al. Prognostic impact of PD-L1 expression in primary gastric and intestinal diffuse large B-cell lymphoma. J Gastroenterol. 2020;55(1):39-50.

35. Gisselbrecht C, Van Den Neste E. How I manage patients with relapsed/refractory diffuse large B cell lymphoma. Br J Haematol. 2018;182(5):633-643.

36. Quinn JJ, Chang HY. Unique features of long non-coding RNA biogenesis and function. Nat Rev Genet. 2016;17(1):47-62.

37. Liu S, Yan G, Zhang J, Yu L. Knockdown of Long Noncoding RNA (IncRNA) Metastasis-Associated Lung Adenocarcinoma Transcript 1 (MALAT1) Inhibits Proliferation, Migration, and Invasion and Promoted Apoptosis By Targeting miR-124 in Retinoblastoma. Oncol Res. Epub 21 May 2017.

38. Chen L, Feng P, Zhu X, et al. Long non-coding RNA Malat1 promotes neurite outgrowth through activation of ERK/MAPK signalling pathway in N2a cells. J Cell Mol Med. 2016;20(11):2102-2110. 
39. Jin Y, Feng SJ, Qiu S, Shao N, Zheng JH. LncRNA MALAT1 promotes proliferation and metastasis in epithelial ovarian cancer via the PI3K/AKT pathway. Eur Rev Med Pharmacol Sci. 2017;21(14):31763184.

40. Liang J, Liang L, Ouyang K, Li Z, Yi X. MALAT1 induces tongue cancer cells' EMT and inhibits apoptosis through Wnt/ $\beta$-catenin signaling pathway. J Oral Pathol Med. 2017;46(2):98-105.

41. Zhao G, Su Z, Song D, Mao Y, Mao X. The long noncoding RNA MALAT1 regulates the lipopolysaccharide-induced inflammatory response through its interaction with NF-KB. FEBS Lett. 2016;590(17):2884-2895.

42. Li Z, Zhu Q, Zhang H, Hu Y, Wang G, Zhu Y. MALAT1: a potential biomarker in cancer. Cancer Manag Res. 2018;10:6757-6768.

43. Wang J, Su L, Chen $X$, et al. MALAT1 promotes cell proliferation in gastric cancer by recruiting SF2/ASF. Biomed Pharmacother. 2014;68(5):557-564.

44. West J, Davis C, Sunwoo H, et al. The long noncoding RNAs NEAT1 and MALAT1 bind active chromatin sites. Mol cell. 2014;55(5):791-802.

45. Tripathi V, Ellis J, Shen Z, et al. The nuclear-retained noncoding RNA MALAT1 regulates alternative splicing by modulating SR splicing factor phosphorylation. Mol cell. 2010;39(6):925-938.

46. Li L, Chai Y, Guo X, Chu S, Zhang L. The effects of the long non-coding RNA MALAT-1 regulated autophagy-related signaling pathway on chemotherapy resistance in diffuse large B-cell lymphoma. Biomed Pharmacother. 2017;89:939-948.

47. International Non-Hodgkin's Lymphoma Prognostic Factors P. A predictive model for aggressive nonHodgkin's lymphoma. N Engl J Med. 1993;329(14):987-994.

48. van Imhoff GW, Boerma EJ, van der Holt B, et al. Prognostic impact of germinal center-associated proteins and chromosomal breakpoints in poor-risk diffuse large B-cell lymphoma. J Clin Oncol. 2006;24(25):4135-4142.

49. Ye H, Lu L, Ge B, et al. MLL2 protein is a prognostic marker for gastrointestinal diffuse large B-cell lymphoma. Int J Clin Exp Pathol. 2015;8(10):13043-13050.

50. Chen F, Liu S, Zhou Y, Shen H, Zuo X. Mad2 overexpression is associated with high cell proliferation and reduced disease-free survival in primary gastrointestinal diffuse large B-cell lymphoma. Hematology. 2016;21(7):399-403.

\section{Tables}

Table 1 Association between clinical characteristics and MALAT1 expression in PGI-DLBCL 


\begin{tabular}{|c|c|c|c|c|}
\hline \multirow[t]{2}{*}{ Characteristics } & \multirow[t]{2}{*}{ Case NO. $(n=90)$} & \multicolumn{2}{|c|}{ MALAT1 expression levels } & \multirow[t]{2}{*}{$P$} \\
\hline & & High $(n=67)$ & Low $(n=23)$ & \\
\hline \multicolumn{5}{|l|}{ Gender } \\
\hline Male & 48 & 35 & 13 & \multirow[t]{2}{*}{0.722} \\
\hline Female & 42 & 32 & 10 & \\
\hline \multicolumn{5}{|l|}{ Age } \\
\hline$\leq 60$ & 39 & 31 & 8 & \multirow[t]{2}{*}{0.337} \\
\hline$>60$ & 51 & 36 & 15 & \\
\hline \multicolumn{5}{|l|}{ Origin } \\
\hline Stomach & 69 & 50 & 19 & \multirow[t]{2}{*}{0.435} \\
\hline Intestinal & 21 & 17 & 4 & \\
\hline \multicolumn{5}{|c|}{ Pathological type } \\
\hline GCB & 37 & 22 & 15 & \multirow[t]{2}{*}{0.006} \\
\hline Non-GCB & 53 & 45 & 8 & \\
\hline \multicolumn{5}{|c|}{ Lugano staging status } \\
\hline$\rrbracket-\bigotimes$ & 40 & 22 & 18 & \multirow[t]{2}{*}{$<0.001$} \\
\hline$\triangle \mathrm{E}-\mathrm{Q}$ & 50 & 45 & 5 & \\
\hline \multicolumn{5}{|l|}{ IPI score } \\
\hline $0-2$ & 54 & 45 & 9 & \multirow[t]{2}{*}{0.018} \\
\hline $3-5$ & 36 & 22 & 14 & \\
\hline \multicolumn{5}{|l|}{ ECOG } \\
\hline $0-1$ & 69 & 49 & 20 & \multirow[t]{2}{*}{0.176} \\
\hline $2-4$ & 21 & 18 & 3 & \\
\hline \multicolumn{5}{|l|}{ B symptoms } \\
\hline Negative & 30 & 20 & 10 & \multirow[t]{2}{*}{0.232} \\
\hline Positive & 60 & 47 & 13 & \\
\hline \multicolumn{5}{|l|}{ LDH level } \\
\hline Normal & 32 & 26 & 6 & \multirow[t]{2}{*}{0.272} \\
\hline Elevated & 58 & 41 & 17 & \\
\hline
\end{tabular}




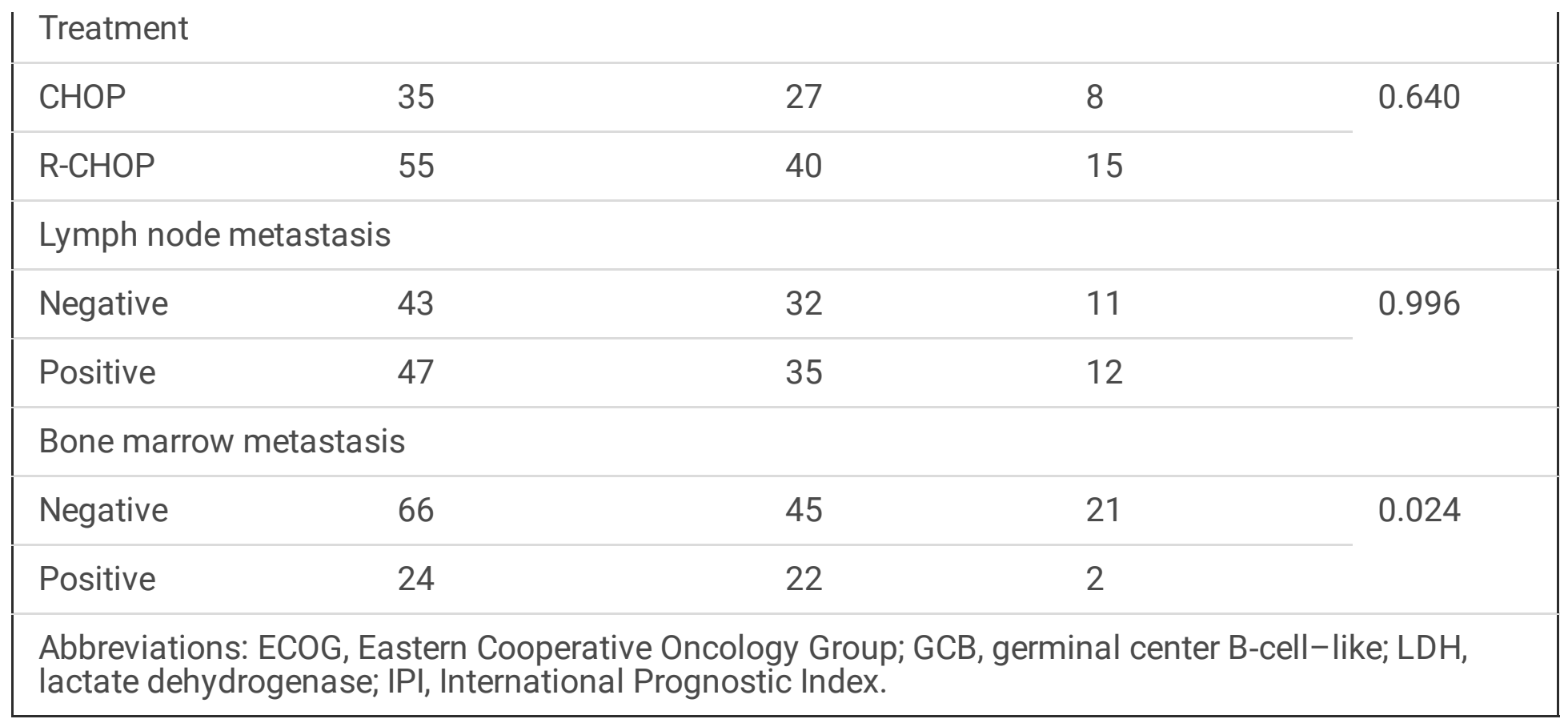

Table 2 Univariate and multivariate analyses of factors associated with PFS and OS of all patients with PGI-DLBCL 


\begin{tabular}{|c|c|c|c|c|c|c|c|c|}
\hline \multirow[t]{3}{*}{ Parameters } & \multicolumn{4}{|c|}{ Univariate analysis } & \multicolumn{4}{|c|}{ Multivariate analysis } \\
\hline & \multicolumn{2}{|l|}{ os } & \multicolumn{2}{|l|}{ PFS } & \multicolumn{2}{|l|}{ os } & \multicolumn{2}{|l|}{ PFS } \\
\hline & $\begin{array}{l}\mathrm{HR}(95 \% \\
\mathrm{Cl})\end{array}$ & $P$ & $\begin{array}{l}\mathrm{HR}(95 \% \\
\mathrm{Cl})\end{array}$ & $P$ & $\begin{array}{l}\mathrm{HR}(95 \% \\
\mathrm{Cl})\end{array}$ & $P$ & $\begin{array}{l}\mathrm{HR} \\
(95 \% \\
\mathrm{Cl})\end{array}$ & $P$ \\
\hline \multicolumn{9}{|l|}{ Gender } \\
\hline $\begin{array}{l}\text { male vs. } \\
\text { female }\end{array}$ & $\begin{array}{l}0.942 \\
(0.607- \\
1.464)\end{array}$ & 0.791 & $\begin{array}{l}0.877 \\
(0.654- \\
1.362)\end{array}$ & 0.559 & & & & \\
\hline \multicolumn{9}{|l|}{ Age } \\
\hline$\leq 60$ vs. $>60$ & $\begin{array}{l}1.127 \\
(0.727- \\
1.746)\end{array}$ & 0.593 & $\begin{array}{l}1.135 \\
(0.733- \\
1.758)\end{array}$ & 0.570 & & & & \\
\hline \multicolumn{9}{|l|}{ Origin } \\
\hline $\begin{array}{l}\text { stomach vs. } \\
\text { intestinal }\end{array}$ & $\begin{array}{l}1.295 \\
(0.809- \\
2.075)\end{array}$ & 0.282 & $\begin{array}{l}1.249 \\
(0.779- \\
2.002)\end{array}$ & 0.356 & & & & \\
\hline \multicolumn{9}{|c|}{ Pathological type } \\
\hline $\begin{array}{l}\text { GCB vs. non- } \\
\text { GCB }\end{array}$ & $\begin{array}{l}2.011 \\
(1.266- \\
3.196)\end{array}$ & 0.003 & $\begin{array}{l}2.130 \\
(1.346- \\
3.373)\end{array}$ & 0.001 & $\begin{array}{l}1.848 \\
(1.071- \\
3.188)\end{array}$ & 0.027 & $\begin{array}{l}1.545 \\
(0.903- \\
2.642)\end{array}$ & 0.112 \\
\hline \multicolumn{9}{|c|}{ Lugano staging status } \\
\hline $\begin{array}{l}\text { I-II vs. IIE- } \\
\text { IV }\end{array}$ & $\begin{array}{l}2.129 \\
(1.293- \\
3.507)\end{array}$ & 0.003 & $\begin{array}{l}1.969 \\
(1.201- \\
3.231)\end{array}$ & 0.007 & $\begin{array}{l}1.107 \\
(0.691- \\
1.773)\end{array}$ & 0.672 & $\begin{array}{l}0.981 \\
(0.612- \\
1.574)\end{array}$ & 0.938 \\
\hline \multicolumn{9}{|l|}{ IPI score } \\
\hline $0-2$ vs. $3-5$ & $\begin{array}{l}1.730 \\
(1.096- \\
2.729)\end{array}$ & 0.018 & $\begin{array}{l}1.742 \\
(1.106- \\
2.746)\end{array}$ & 0.017 & $\begin{array}{l}1.980 \\
(1.047- \\
3.747)\end{array}$ & 0.036 & $\begin{array}{l}2.316 \\
(1.253- \\
4.282)\end{array}$ & 0.007 \\
\hline \multicolumn{9}{|l|}{ ECOG } \\
\hline $0-2$ vs. $3-5$ & $\begin{array}{l}0.797 \\
(0.504- \\
1.261)\end{array}$ & 0.333 & $\begin{array}{l}0.731 \\
(0.463- \\
1.156)\end{array}$ & 0.180 & & & & \\
\hline \multicolumn{9}{|l|}{ B symptoms } \\
\hline $\begin{array}{l}\text { negative vs. } \\
\text { positive }\end{array}$ & $\begin{array}{l}1.610 \\
(1.007- \\
2.574)\end{array}$ & 0.047 & $\begin{array}{l}1.316 \\
(0.825- \\
2.099)\end{array}$ & 0.249 & & & & \\
\hline
\end{tabular}




\begin{tabular}{|c|c|c|c|c|c|c|c|c|}
\hline $\begin{array}{l}\text { normal vs. } \\
\text { elevated }\end{array}$ & $\begin{array}{l}0.824 \\
(0.534- \\
1.271)\end{array}$ & 0.382 & $\begin{array}{l}0.719 \\
(0.465- \\
1.110)\end{array}$ & 0.136 & & & & \\
\hline \multicolumn{9}{|l|}{ Treatment } \\
\hline $\begin{array}{l}\text { CHOP vs. R- } \\
\text { CHOP }\end{array}$ & $\begin{array}{l}1.058 \\
(0.684- \\
1.636)\end{array}$ & 0.801 & $\begin{array}{l}1.124 \\
(0.726- \\
1.741)\end{array}$ & 0.599 & & & & \\
\hline \multicolumn{9}{|c|}{ Lymph node metastasis } \\
\hline $\begin{array}{l}\text { negative vs. } \\
\text { positive }\end{array}$ & $\begin{array}{l}0.710 \\
(0.459- \\
1.098)\end{array}$ & 0.123 & $\begin{array}{l}0.701 \\
(0.452- \\
1.086)\end{array}$ & 0.112 & & & & \\
\hline \multicolumn{9}{|c|}{ Bone marrow metastasis } \\
\hline $\begin{array}{l}\text { negative vs. } \\
\text { positive }\end{array}$ & $\begin{array}{l}0.543 \\
(0.344- \\
0.855)\end{array}$ & 0.008 & $\begin{array}{l}0.503 \\
(0.320- \\
0.791)\end{array}$ & 0.003 & $\begin{array}{l}0.928 \\
(0.529- \\
1.628)\end{array}$ & 0.795 & $\begin{array}{l}0.921 \\
(0.529- \\
1.603)\end{array}$ & 0.772 \\
\hline \multicolumn{9}{|c|}{ MALAT1 expression } \\
\hline Low vs. high & $\begin{array}{l}1.875 \\
(1.200- \\
2.931)\end{array}$ & 0.006 & $\begin{array}{l}1.780 \\
(1.137- \\
2.786)\end{array}$ & 0.012 & $\begin{array}{l}1.966 \\
(1.024- \\
3.771)\end{array}$ & 0.042 & $\begin{array}{l}2.252 \\
(1.187- \\
4.274)\end{array}$ & 0.013 \\
\hline
\end{tabular}

Figures 


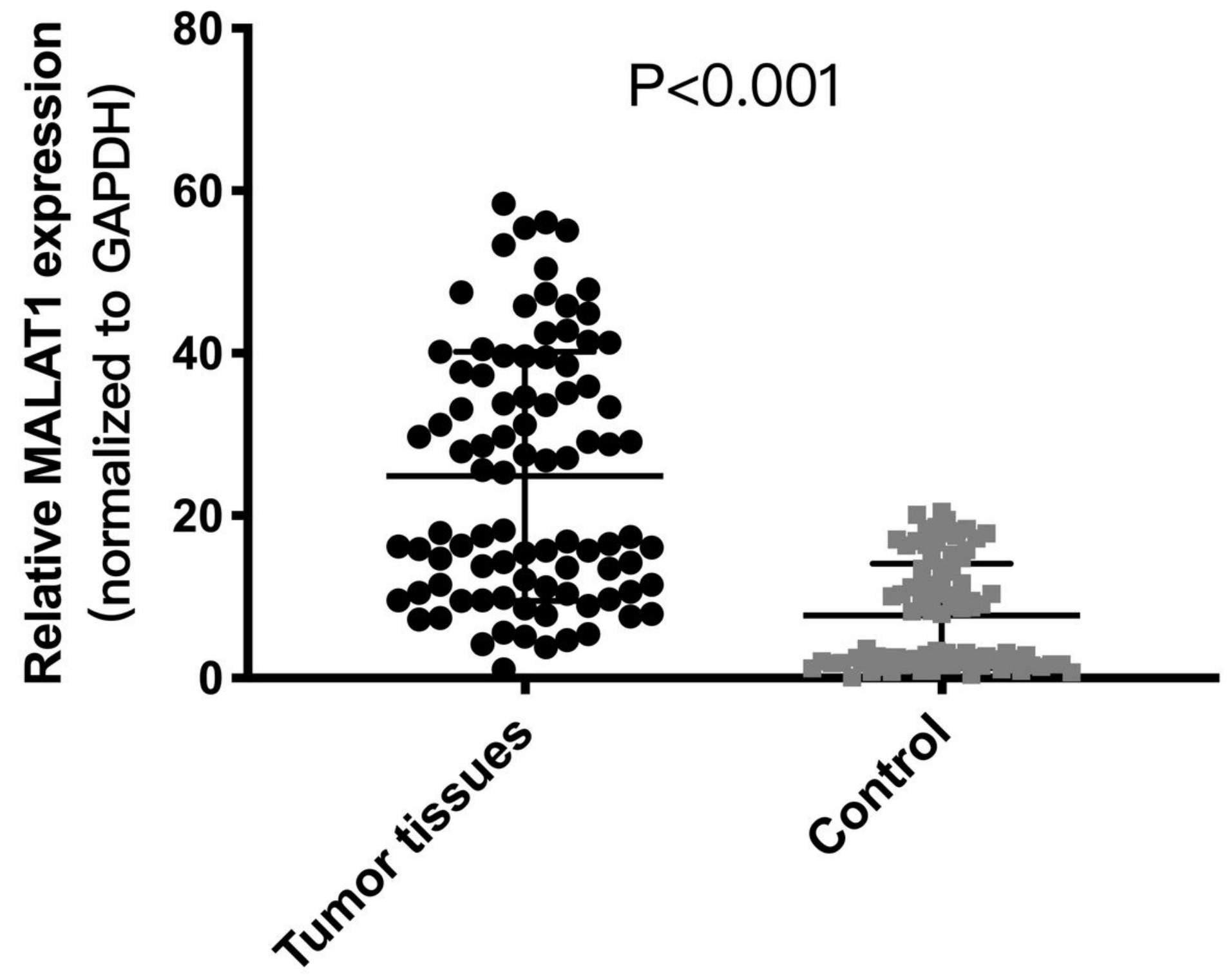

Figure 1

MALAT1 is highly expressed in PGI-DLBCL tissues. The relative expression of MALAT1 in PGI-DLBCL tissues, compared with adjacent noncancerous tissues $(P<0.001)$. Data were presented as the mean \pm SEM of three independent experiments. 


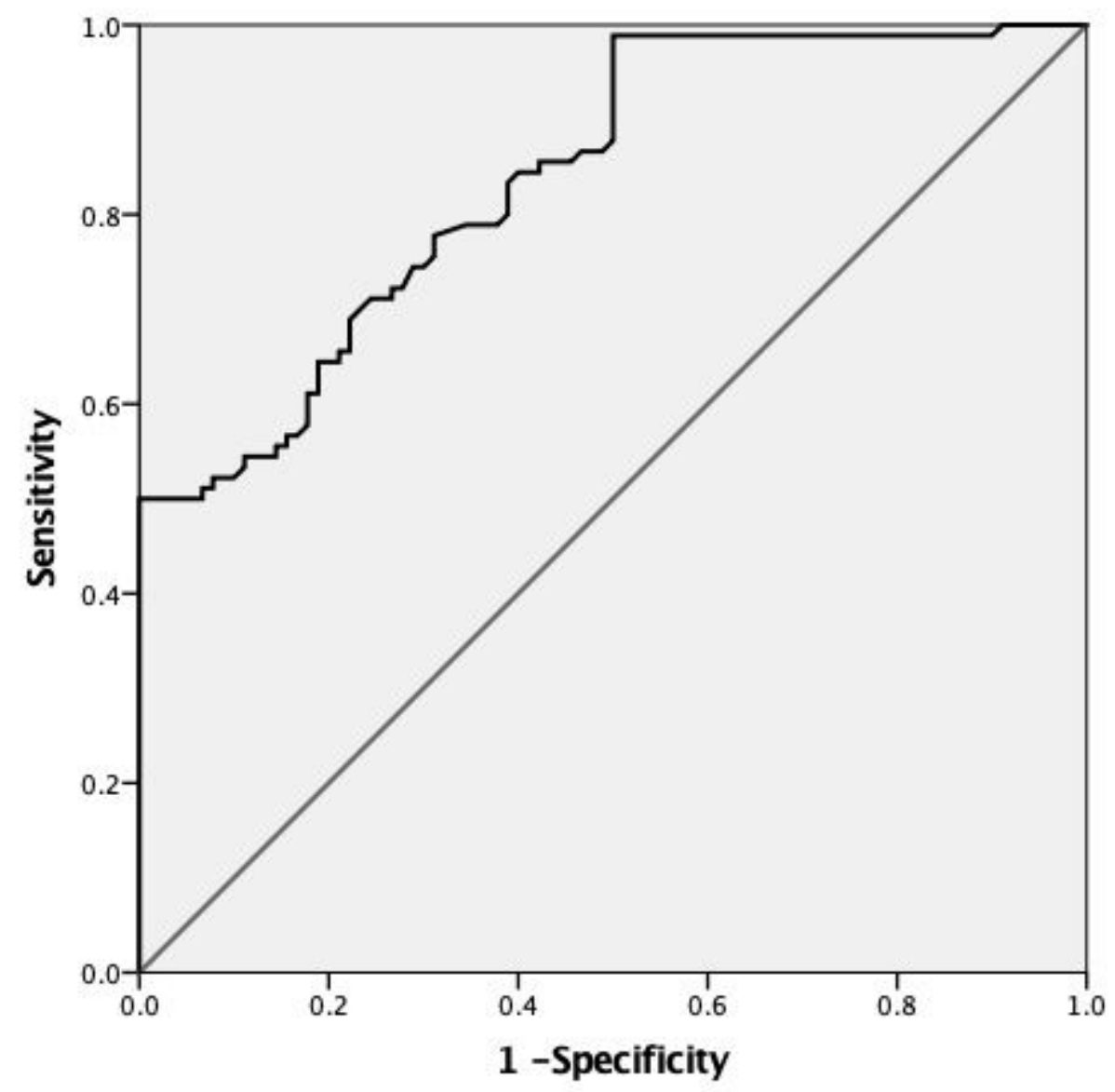

Figure 2

ROC curve analysis showing performance of MALAT1 expression to discriminate between with PGIDLBCL tissues and normal tissues. MALAT1 showed high sensitivity and specificity for the diagnosis of PGI-DLBCL $(P<0.001)$. The most discriminative cutoff concentration of MALAT1 was 11.4 with an AUC value of 0.838 . The sensitivity and specificity were $75.6 \%$ and $70.0 \%$, respectively. 

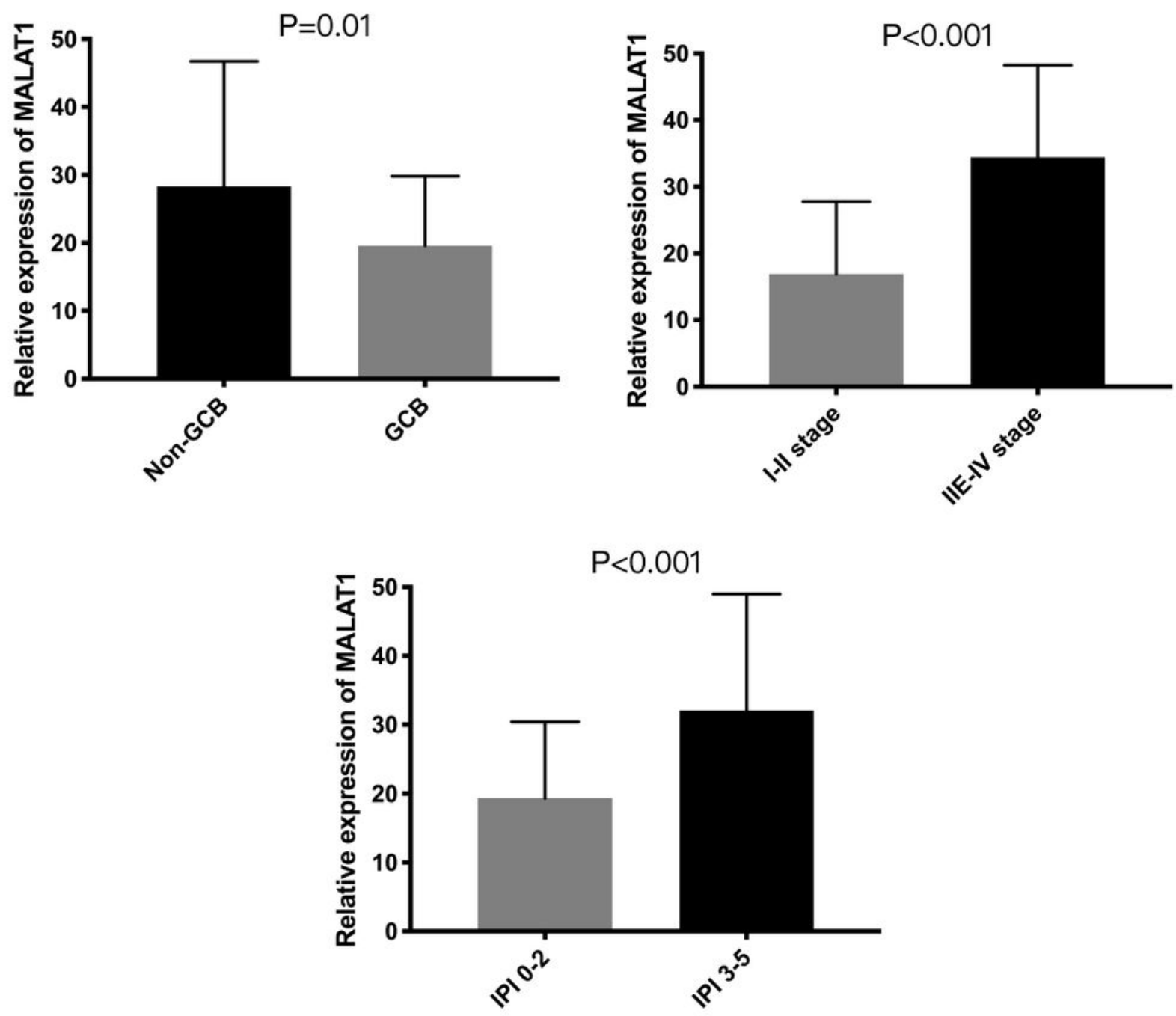

Figure 3

The expression levels of MALAT1 is associated with clinicopathological features of patients with PGI-DLBCL. MALAT1 is highly expressed in the non-GCB group (a), advanced stage (IIE-IV) group (b), and high IPI (3-5) group (c). 

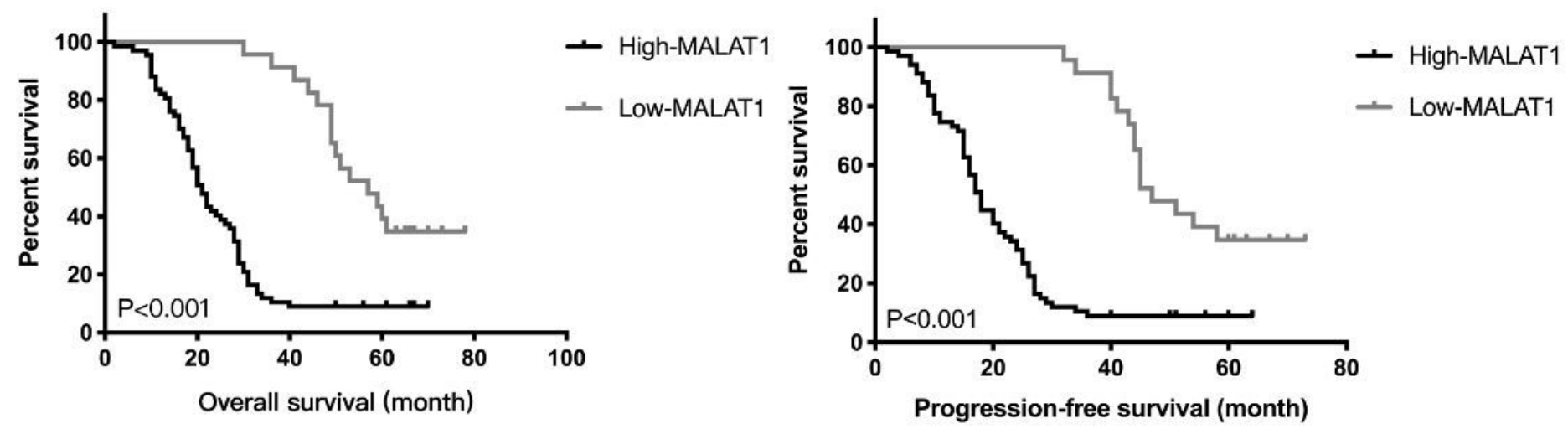

\section{Figure 4}

Kaplan-Meier analysis of overall survival and progression-free survival according to MALAT1 expression levels. Upregulation of MALAT1 showed a correlation with poor overall survival (a) and progression-free survival (b) of patients with PGI-DLBCL. 